\title{
Medical Findings in Women with Anorexia Nervosa in a Korean Population
}

\author{
Youl-Ri Kim ${ }^{1,2} \bowtie$, Myung Ha Son ${ }^{1}$, Jong Chun $\mathrm{Nah}^{3}$ and Hyun Ah Park ${ }^{4}$ \\ ${ }^{1}$ Department of Neuropsychiatry, Seoul Paik Hospital, Inje University, Seoul, Republic of Korea \\ ${ }^{2}$ Institute for Gender Research, Seoul National University, Seoul, Republic of Korea \\ ${ }^{3}$ Department of Internal Medicine, Seoul Paik Hospital, Inje University, Seoul, Republic of Korea \\ ${ }^{4}$ Department of Family Medicine, Seoul Paik Hospital, Inje University, Seoul, Republic of Korea
}

Objective Eating disorders are a common clinical problem among young women in Asian countries. The aim of this study is to determine the medical effects of anorexia nervosa (AN) in the Korean population.

Methods We comprehensively investigated medical complications including haemodynamic, haematologic, endocrine, and bone density abnormalities in 67 Korean women with AN, together with 194 healthy Korean women of comparable age with a cross-sectional design.

Results In AN, 36.9\% were anaemic, 50.8\% were leukopenic, 35.5\% were hypoproteinemic, 7.9\% were hypokalemic, $9.5 \%$ had increased alanine aminotransferase, $6.3 \%$ were hyperbilirubinemia, $14.5 \%$ were hypercholesterolemia, $14.8 \%$ had decreased triiodothyronine. Osteopenia at any one site was identified in $43.3 \%$ and an additional $13.4 \%$ had osteoporosis. The lowest-ever body mass index was the main determinant of bone mineral density.

Conclusion Our data in Korean patients with AN show high frequencies of laboratory abnormalities for medical complications. This study emphasizes the importance of recognizing AN as a medical risk in young Korean women. Psychiatry Investig 2013;10:101-107

Key Words Anorexia nervosa, Eating disorder, Medical complication, Bone mineral density, Korean.

\section{INTRODUCTION}

The core features of anorexia nervosa (AN) are the pursuit of weight loss and the resultant low body weight. The nutritional compromise of AN results in amenorrhea, increased medical risks, and an eventual increase in mortality. The mortality rate of $\mathrm{AN}$ is $5.6 \%,{ }^{1}$ which is 12 times the rate of healthy age-matched women. The underlying medical causes of the increased standardized mortality rate (SMR) were found to be cardiovascular, endocrine, haematopoietic, autoimmune, respiratory, and urogenital in nature. ${ }^{2}$ The medical consequences of AN on bones can create long-term problems, such as growth retardation starting from adolescent $\mathrm{AN}$ and, finally, osteoporosis in adult AN. In a study carried out in the

Received: November 19, 2012 Revised: January 3, 2013

Accepted: January 24, 2013 Available online: May 30, 2013

$\triangle$ Correspondence: Youl-Ri Kim, MD, PhD

Department of Neuropsychiatry, Seoul-Paik Hospital, Inje University, $9 \mathrm{Ma}-$ reunnae-ro, Jung-gu, Seoul 100-032, Republic of Korea

Tel: +82-2-2270-0063, Fax: +82-2-2270-0344, E-mail: youlri.kim@paik.ac.kr

(a) This is an Open Access article distributed under the terms of the Creative Commons Attribution Non-Commercial License (http://creativecommons.org/licenses/bync/3.0) which permits unrestricted non-commercial use, distribution, and reproduction in any medium, provided the original work is properly cited.
United States, the prevalence of $\mathrm{AN}$ were found to be anaemia $38.6 \%$, leukocytopenia $34.4 \%$, hyponatremia $19.7 \%$, hypokalemia $19.7 \%$, bradycardia $41.3 \%$, hypotension $16.1 \%$, elevation of alanine aminotransferase $12.2 \%$, osteopenia $51.7 \%$, and osteoporosis $34.6 \%$. $^{3}$ Skeptical attitudes regarding the medical risks and long-term compromised medical status, particularly in chronic cases with underestimated subjective signs and symptoms of medical risk, contribute to delayed diagnosis of the medical complications in patients with AN.

Whereas awareness that eating disorders are a common clinical problem among young women in high income Asian societies, ${ }^{4}$ there have been few comprehensive studies on the medical complications of AN in Korean population. Cross cultural studies of AN showed little evidence for any major differences in the psychological or environmental risk factors for AN between Korean and British women. ${ }^{5,6}$ When considering the ethnic differences in the bone mass of healthy wom$\mathrm{en}^{7}$ and the arguments for lowering of the goal of body mass index (BMI) in the management of AN in Asian patients, ${ }^{8}$ the medical complications for Korean patients with AN need further research. Therefore, we investigated the medical findings in Korean patients with AN. The primary aim of this research 
was to investigate the prevalence of AN related medical findings including haematologic, biochemical, and bone density in a Korean population as compared with healthy women of comparable age. Our hypothesis was the Korean women with AN have a higher prevalence of medical complications than healthy Korean women.

\section{METHODS}

\section{Participants}

This study was carried out retrospectively in the specialized eating disorders unit of the tertiary referral university hospital in Seoul, S. Korea, which can accommodate both inpatients and outpatients. All 67 adult patients with AN who visited the clinic for a first assessment from August 2010 to February 2012 were included. The data of patients who had taken any form of medication including oral contraceptives or hormone replacement therapy were excluded from the study. The diagnosis of AN, as defined by the Diagnostic and Statistical Manual of Mental Disorders, Fourth Edition (DSM-IV), ${ }^{9}$ was confirmed in all patients from the consensus by one psychiatrist and two psychologists. Thirty seven patients were diagnosed with the restricting type and 30 with the binge purging type. Control participants were recruited from people who were seeking routine standard medical check-up, in a health promotion centre of the hospital from August 2010 to February 2012. Control participants who did not suffer from any medical/psychiatric disorders requiring clinical attention, were included based on their screening questionnaire. The control women were assessed for the same parameters as AN patients, except for female hormone and amylase levels. This study was approved by the Institutional Review Board of Seoul Paik Hospital in Seoul, S. Korea.

\section{Measurements}

The data included laboratory parameters (sodium, potassium, chloride, calcium, blood urea nitrogen, creatinine, aspartate aminotransferase, alanine aminotransferase, albumin, total protein, estradiol, luteinizing hormone, follicular-stimulating hormone, thyrotropin, and thyroxine) as well as demographics and illness characteristics based on the clinical assessment. The body mass index (BMI) [weight in $\mathrm{kg} /$ (height in $\mathrm{m})^{2}$ ] was calculated. The bone mineral density (BMD) was measured by dual X-ray absorptiometry (DXA, Lunar, GE Healthcare, US) at the lumbar spine (L1-L4 and L2-L4), and the femoral neck. The BMD results were expressed as grams per centimetre squared and t-score [defined as the number of standard deviations (SDs) below the mean value of young Korean women] as well as z-score (calculated by comparing BMD with a reference Korean population, which is matched for age and sex). Quality control was performed according to the usual standards.

\section{Statistical analysis}

The differences between the AN and control participants were analysed using the unpaired Student's t-test. Pearson correlations were performed between the laboratory measurements, with scales measuring the severity of AN. Multiple linear regression analyses were used to study the associations between the clinical variables (independent variables) and sitespecific BMDs (dependent variables). The significance levels were set to $\mathrm{p}<0.05$. All analyses were performed using SPSS 19.0 for Windows (IBM). Data are presented as mean and standard deviation.

\section{RESULTS}

\section{Clinical characteristics}

The clinical characteristics of the patients with AN are shown in Table 1. The average onset age of AN was 20.96 44.13 years and the mean duration since diagnosis of AN was 64.08 \pm 73.27 months. The current BMI was lower in the women with AN than in the control participants, as expected. The women with restricting type of AN (RAN) and binge eating and purging type of AN (BPAN) did not differ in their current, highest or lowest BMI, age of onset or duration of illness.

\section{Haematologic status}

The mean values of the different haematologic parameters in the women with $\mathrm{AN}$ and the corresponding control subjects are shown in Table 2. Among the women with AN, 36.9\% had anaemia, as indicated by a haematocrit level below the normal range (normal range, 36-46\%). Leukocytopenia for the white blood cell count occurred in 50.0\% (normal range 4500$13000 / \mu \mathrm{L}$ ) and thrombocytopenia in $4.7 \%$ (normal range, $150000-350000 / \mu \mathrm{L}$ ) of the women with AN. The total red cell blood count, haemoglobin, haematocrit, and white blood cells were significantly lower in the women with AN than in the control subjects (all $\mathrm{p}$ values $<0.001$ ). The platelet count did not differ between the women with $\mathrm{AN}$ and corresponding control subjects. There was a positive correlation between the red cell blood count, haemoglobin or haematocrit count and the lowest-ever or current BMI. There was no significant difference in the haematologic status between RAN and BPAN.

\section{Biochemical data}

The biochemical data are shown in Table $3.1 .6 \%$ of the women with AN had hyponatremia (normal range, $135-145 \mathrm{mEq} /$ L) and 7.9\% of them were hypokelemic (normal range, 3.4-4.8 $\mathrm{mEq} / \mathrm{L}) .6 .3 \%$ of the women with AN had increased aspar- 
Table 1. Clinical characteristics in women with $A N$ and healthy women

\begin{tabular}{|c|c|c|c|c|c|c|c|c|}
\hline \multirow{3}{*}{ Clinical variables } & \multicolumn{5}{|c|}{ Women with AN } & \multirow{3}{*}{$\begin{array}{l}\text { Healthy } \\
\text { women } \\
(\mathrm{N}=194)\end{array}$} & \multirow{2}{*}{\multicolumn{2}{|c|}{$\begin{array}{l}\text { Comparison of } \\
\text { AN with healthy } \\
\text { women }\end{array}$}} \\
\hline & \multirow{2}{*}{$\begin{array}{l}\text { AN, total } \\
(\mathrm{N}=67)\end{array}$} & \multirow{2}{*}{$\begin{array}{c}\text { RAN } \\
(\mathrm{N}=37)\end{array}$} & \multirow{2}{*}{$\begin{array}{l}\text { BPAN } \\
(\mathrm{N}=30)\end{array}$} & \multicolumn{2}{|c|}{$\begin{array}{l}\text { Comparison of } \\
\text { RAN with BPAN }\end{array}$} & & & \\
\hline & & & & $\mathrm{t}(\mathrm{df}=65)$ & $\mathrm{p}$-value & & $\mathrm{t}(\mathrm{df}=259)$ & $\mathrm{p}$-value \\
\hline Age (years) & $25.62(6.02)$ & $25.89(6.82)$ & $25.30(4.95)$ & 0.398 & 0.692 & $26.52(2.07)$ & -1.790 & 0.075 \\
\hline \multicolumn{9}{|l|}{ BMI } \\
\hline Current $\left(\mathrm{kg} / \mathrm{m}^{2}\right)$ & $15.86(1.93)$ & $15.68(2.30)$ & $16.09(1.37)$ & -0.856 & 0.395 & $20.15(2.75)$ & -11.713 & $<0.001$ \\
\hline Highest ever $\left(\mathrm{kg} / \mathrm{m}^{2}\right)$ & $22.26(3.00)$ & $22.08(2.68)$ & $22.49(3.38)$ & -0.549 & 0.585 & NA & NA & NA \\
\hline Lowest ever $\left(\mathrm{kg} / \mathrm{m}^{2}\right)$ & $14.43(1.83)$ & $14.09(2.11)$ & $14.85(1.37)$ & -1.664 & 0.101 & NA & NA & NA \\
\hline Onset (years) & $20.96(4.13)$ & $21.56(4.72)$ & $20.23(3.21)$ & 1.302 & 0.198 & NA & NA & NA \\
\hline Duration (months) & $63.96(73.27)$ & $56.14(72.87)$ & $73.60(73.83)$ & -0.964 & 0.339 & NA & NA & NA \\
\hline
\end{tabular}

Data are shown as mean (s.d.). p-value $<0.05$ defined as significant. AN: anorexia nervosa, RAN: anorexia nervosa, restricting type, BPAN: anorexia nervosa, binge purging type, BMI: body mass index, NA: not applicable

Table 2. Hematologic parameters in women with AN and healthy women

\begin{tabular}{|c|c|c|c|c|c|c|c|c|}
\hline & \multicolumn{5}{|c|}{ Women with AN } & \multirow{3}{*}{$\begin{array}{l}\text { Healthy } \\
\text { women } \\
(\mathrm{N}=194)\end{array}$} & \multirow{2}{*}{\multicolumn{2}{|c|}{$\begin{array}{l}\text { Comparison of } \\
\text { AN with healthy } \\
\text { women }\end{array}$}} \\
\hline & \multirow{2}{*}{$\begin{array}{l}\text { AN, total } \\
(\mathrm{N}=65)\end{array}$} & \multirow{2}{*}{$\begin{array}{c}\text { RAN } \\
(\mathrm{N}=37)\end{array}$} & \multirow{2}{*}{$\begin{array}{l}\text { BPAN } \\
(\mathrm{N}=28)\end{array}$} & \multicolumn{2}{|c|}{$\begin{array}{c}\text { Comparison of } \\
\text { RAN with BPAN }\end{array}$} & & & \\
\hline & & & & $t(d f=63)$ & $\mathrm{p}$-value & & $t(d f=257)$ & p-value \\
\hline $\mathrm{RBC}\left(10^{6} / \mathrm{mm}^{3}\right)$ & $3.99(0.51)$ & $3.90(0.55)$ & $4.10(0.45)$ & -1.542 & 0.128 & $4.43(0.29)$ & -8.886 & $<0.001$ \\
\hline $\mathrm{Hb}(\mathrm{g} / \mathrm{Dl})$ & $11.86(1.80)$ & $11.76(1.80)$ & $11.98(1.89)$ & -0.475 & 0.637 & $13.03(1.01)$ & -6.588 & $<0.001$ \\
\hline Hct (\%) & $36.00(4.77)$ & $35.34(4.60)$ & $36.86(5.09)$ & -1.259 & 0.213 & $38.96(2.56)$ & -6.443 & $<0.001$ \\
\hline WBC $\left(10^{3} / \mathrm{mm}^{3}\right)$ & $4.52(1.58)$ & $4.47(1.69)$ & $4.59(1.47)$ & -0.284 & 0.777 & $5.90(1.66)$ & -5.731 & $<0.001$ \\
\hline Platelet $\left(10^{3} / \mathrm{mm}^{3}\right)$ & $244(80.66)$ & $247.58(93.11)$ & $239.36(58.33)$ & 0.409 & 0.684 & $257.33(53.74)$ & -1.183 & 0.238 \\
\hline
\end{tabular}

Data are shown as mean (s.d.). p-value $<0.05$ defined as significant after Bonferroni correction. AN: anorexia nervosa, RAN: anorexia nervosa, restricting type, BPAN: anorexia nervosa, binge purging type, RBC: red blood cell count, Hb: hemoglobin, Hct: Hematocrit, WBC: white blood cell

tate aminotransferase and 9.5\% had increased alanine aminotransferase. The frequency of hyperbilirubinemia was $6.3 \%$ in the patients with AN. The level of serum bilirubin in the patients with AN was lower than that in the healthy women $(\mathrm{p}<$ 0.001). $35.5 \%$ of the women with $\mathrm{AN}$ had hypoproteinemia (normal range 6.7-8.3 g/dL) and 1.6\% had hypoalbuminemia (normal range $3.5-5.2 \mathrm{~g} / \mathrm{dL}$ ). $14.5 \%$ of the women with $\mathrm{AN}$ had hypercholesterolemia (normal range 150-240/ $\mu \mathrm{L}$ ). The women with AN had significantly lower serum albumin levels, as well as lower bilirubin levels, than the corresponding healthy women $(\mathrm{p}<0.001)$. They also had higher blood urea nitrogen levels $(p<0.001)$ and cholesterol levels $(p<0.001)$, but lower levels of triiodothyronine $(\mathrm{p}<0.001)$ and thyroid stimulating hormone $(\mathrm{p}<0.001)$, than the healthy women.

The serum amylase and female sex hormonal levels were measured only in the AN patients (Table 4). The secretion of follicular stimulating hormone (FSH) and lutenizing hormone (LH) were decreased from their normal levels, as was the secretion of estrogen from the ovary. Our data suggested that the hypothalamic-pituitary-gonadal axis was regressed to that of a prepubertal child in the AN women, as was report- ed previously in a Caucasian population. There was no difference in the female sex hormone levels, i.e., LH, FSH, and estrogen between the subtypes of AN. As expected, the serum amylase level was higher in the women with the binge purging type of AN than in those with the restricting type of $\mathrm{AN}(\mathrm{p}<0.001)$.

We explored the correlation of the laboratory results with clinical variable, such as the lowest and current BMI, age at onset and duration of illness. The severity of the biochemical laboratory findings are generally correlated with the severity of the current BMI. The serum levels of haemoglobin, haematocrit, protein, glucose, triiodothyronine, LH and estrogen were positively correlated with the current BMI. The serum level of aspartate aminotransferase was negatively correlated with both the lowest ever BMI and the current BMI. The serum level of alanine aminotransferase was more correlated with the lowest ever BMI than the current BMI.

\section{Skeletal health}

All measures of BMD were lower in the women with AN than in the controls. Table 5 shows the proportion of women 
Table 3. Biochemical parameters in women with AN and healthy women

\begin{tabular}{|c|c|c|c|c|c|c|c|c|}
\hline & \multicolumn{5}{|c|}{ Women with AN } & \multirow{3}{*}{$\begin{array}{l}\text { Healthy } \\
\text { women } \\
(\mathrm{N}=194)\end{array}$} & \multirow{2}{*}{\multicolumn{2}{|c|}{$\begin{array}{l}\text { Comparison of } \\
\text { AN with healthy } \\
\text { women }\end{array}$}} \\
\hline & \multirow{2}{*}{$\begin{array}{c}\mathrm{AN} \\
(\mathrm{N}=65)\end{array}$} & \multirow{2}{*}{$\begin{array}{c}\text { RAN } \\
(\mathrm{N}=37)\end{array}$} & \multirow{2}{*}{$\begin{array}{l}\text { BPAN } \\
(\mathrm{N}=28)\end{array}$} & \multicolumn{2}{|c|}{$\begin{array}{c}\text { Comparison of } \\
\text { RAN with BPAN }\end{array}$} & & & \\
\hline & & & & $t(d f=63)$ & $\mathrm{p}$-value & & $\mathrm{t}(\mathrm{df}=257)$ & $\mathrm{p}$-value \\
\hline $\mathrm{Na}(\mathrm{mEq} / \mathrm{L})$ & $140.45(2.82)$ & $140.14(3.15)$ & $140.89(2.36)$ & -1.047 & 0.299 & $140.43(1.60)$ & 0.047 & 0.963 \\
\hline $\mathrm{K}(\mathrm{mEq} / \mathrm{L})$ & $3.96(0.49)$ & $3.93(0.54)$ & $3.97(0.42)$ & -0.270 & 0.788 & $4.04(0.33)$ & -1.500 & 0.135 \\
\hline $\operatorname{AST}(\mathrm{U} / \mathrm{L})$ & $28.85(22.97)$ & $32.00(29.65)$ & $23.61(5.21)$ & 1.643 & 0.109 & $18.89(4.25)$ & 5.770 & $<0.001$ \\
\hline ALT (U/L) & $25.60(25.04)$ & $32.00(31.70)$ & $17.46(9.18)$ & 2.581 & 0.014 & $13.96(6.37)$ & 5.942 & $<0.001$ \\
\hline Albumin (g/dL) & $4.26(0.43)$ & $4.31(0.43)$ & $4.22(0.47)$ & 0.755 & 0.453 & $4.44(0.20)$ & -4.412 & $<0.001$ \\
\hline Glucose (mg/dL) & $80.14(15.48)$ & $77.74(15.93)$ & $83.25(15.15)$ & -1.394 & 0.168 & $82.51(7.38)$ & -1.650 & 0.100 \\
\hline Bilirubin (mg/dL) & $0.65(0.36)$ & $0.67(0.39)$ & $0.63(0.33)$ & 0.394 & 0.695 & $0.86(0.31)$ & -4.512 & $<0.001$ \\
\hline ALP (IU/L) & $56.56(17.73)$ & $54.15(17.42)$ & $60.11(18.40)$ & -1.295 & 0.200 & $52.68(12.07)$ & 1.956 & 0.052 \\
\hline BUN (mg/dL) & $12.77(7.83)$ & $14.20(9.52)$ & $11.21(4.97)$ & 1.501 & 0.139 & $11.14(3.05)$ & 2.409 & 0.017 \\
\hline Creatinine $(\mathrm{mg} / \mathrm{dL})$ & $0.79(0.20)$ & $0.73(0.22)$ & $0.88(0.13)$ & -3.524 & 0.001 & $0.79(0.13)$ & 0.069 & 0.945 \\
\hline Cholesterol (mg/dL) & $188.08(47.09)$ & $185.51(53.59)$ & $193.85(37.62)$ & -0.688 & 0.494 & $174.40(31.79)$ & 2.624 & 0.009 \\
\hline $\mathrm{TSH}(\mu \mathrm{g} / \mathrm{mL})$ & $1.35(0.85)$ & $1.41(1.07)$ & $1.26(0.52)$ & 0.705 & 0.484 & $1.98(1.14)$ & -4.054 & $<0.001$ \\
\hline $\mathrm{T} 3(\mathrm{pg} / \mathrm{mL})$ & $0.82(0.26)$ & $0.81(0.33)$ & $0.82(0.18)$ & -0.080 & 0.937 & $1.01(0.17)$ & -6.892 & $<0.001$ \\
\hline
\end{tabular}

Data are shown as mean (s.d.). p-value $<0.05$ defined as significant after Bonferroni correction. AN: anorexia nervosa, RAN: anorexia nervosa, restricting type, BPAN: anorexia nervosa, binge purging type, AST: aspartate aminotransferase, ALT: alanine aminotransferase, BUN: blood urea nitrogen, TSH: thyroid stimulating hormone, T3: triiodothyronine

Table 4. Amylase and female sex hormonal levels in women with AN

\begin{tabular}{lcccccc}
\hline & AN, total & RAN & BPAN & \multicolumn{2}{c}{ Comparison of RAN with BPAN } \\
\cline { 5 - 7 } & $(\mathrm{N}=60)$ & $(\mathrm{N}=36)$ & $(\mathrm{N}=24)$ & $\mathrm{t}(\mathrm{df}=58)$ & $\mathrm{p}$-value \\
\hline Amylase, U/L (normal range 0-75 U/L) & $256.65(136.42)$ & $187.11(134.11)$ & $340.17(103.11)$ & -4.731 & $<0.001$ \\
LH, U/L (normal range 1.9-12.5 U/L) & $2.54(5.87)$ & $1.83(2.26)$ & $3.42(6.01)$ & -1.299 & 0.171 \\
FSH, U/L (normal range 2.5-10.2 U/L) & $4.30(2.42)$ & $4.07(2.42)$ & $4.59(2.28)$ & -0.843 & 0.403 & 0.763 \\
Estrogen, pg/mL (normal range 12.5-166 pg/mL) & $30.50(43.7)$ & $31.85(43.79)$ & $28.84(28.08)$ & 0.304 & 0.763 \\
\hline
\end{tabular}

Data are shown as mean (s.d.). p-value $<0.05$ defined as significant. Normal range for female sex hormonal levels were presented referring to follicular phase. AN: anorexia nervosa, RAN: anorexia nervosa, restricting type, BPAN: anorexia nervosa, binge purging type, LH: lutenizing hormone, FST: follicular stimulating hormone

with $\mathrm{AN}$ and control women with $\mathrm{T}$ scores $<-1$ and $<-2.5$ at the different sites examined. Bone density $\mathrm{T}$ scores of -1 at any one site were noted in $43.3 \%$ of the women with AN and an additional $13.4 \%$ had bone density $\mathrm{T}$ scores of -2.5 .

To identify the contribution of the confounders to BMD, a multiple regression analysis was performed with lumbar spine and femoral neck BMD as dependent variables, and the age, current BMI, lowest-ever BMI, duration of illness, and estrogen level as independent variables (Table 6). When controlled for these factors, the lowest-ever BMI was the main determinant of lumbar spine BMD, whereas both the current age and lowest-ever BMI were significant determinants of BMD in the femoral neck bone.

\section{DISCUSSION}

This study reports the overall prevalence of medical abnor- malities in Korean women with AN based on an analysis of 67 patients with a mean duration illness of more than 6 years. Our findings demonstrate a high prevalence of anaemia (36\%) and leukocytopenia (50.0\%) in Korean women with AN. Though the degree of leukocytopenia was mild in the patients with $\mathrm{AN}$ in our Korean population $(4.52 \pm 1.58 / \mu \mathrm{L})$, its frequency was higher than that reported previously ${ }^{10}$ and was also higher than the frequency of anaemia. Leukocytopenia in AN could be the reason for the respiratory cause of death with SMR of 11.5, ${ }^{2}$ urogenital cause of death (SMR 10.8) ${ }^{2}$ and death from infectious diseases (i.e., pneumonia and pyelonephritis). The observed positive correlations between the current, as well as the lowest ever, BMI and red blood cell count, haemoglobin, and haematocrit as reported previously, ${ }^{11}$ which suggest not only the contribution of dietary deficiencies of serum folate, vitamin B12, and iron, but also that of AN to bone marrow suppression and hypoplasia. ${ }^{10}$ 
Table 5. Data for bone mineral density at different sites in women with AN and healthy women

\begin{tabular}{|c|c|c|c|c|c|c|c|c|}
\hline & \multicolumn{5}{|c|}{ Women with AN } & \multirow{3}{*}{$\begin{array}{l}\text { Healthy } \\
\text { women } \\
(\mathrm{N}=194)\end{array}$} & \multirow{2}{*}{\multicolumn{2}{|c|}{$\begin{array}{c}\text { Comparisons of } \\
\text { AN with healthy } \\
\text { women }\end{array}$}} \\
\hline & \multirow{2}{*}{$\begin{array}{l}\text { AN, total } \\
(\mathrm{N}=67)\end{array}$} & \multirow{2}{*}{$\begin{array}{c}\text { RAN } \\
(\mathrm{N}=37)\end{array}$} & \multirow{2}{*}{$\begin{array}{l}\text { BPAN } \\
(\mathrm{N}=30)\end{array}$} & \multicolumn{2}{|c|}{$\begin{array}{c}\text { Comparison of } \\
\text { RAN with BPAN }\end{array}$} & & & \\
\hline & & & & $t(d f=65)$ & $\mathrm{p}$-value & & $t(d f=259)$ & p-value \\
\hline $\mathrm{L} 1-\mathrm{L} 4\left(\mathrm{~g} / \mathrm{cm}^{2}\right)$ & $0.997(0.128)$ & $0.992(0.126)$ & $1.001(0.133)$ & 0.346 & 0.730 & $1.143(0.122)$ & 8.929 & $<0.001$ \\
\hline L1-L4 (Z score) & $-0.670(1.041)$ & $-0.751(1.090)$ & $-0.574(0.990)$ & 0.682 & 0.498 & $0.019(1.033)$ & 4.615 & $<0.001$ \\
\hline L1-L4 (T score) & $-1.164(1.117)$ & $-1.258(1.146)$ & $-1.053(1.091)$ & 0.736 & 0.464 & $0.109(1.048)$ & 8.544 & $<0.001$ \\
\hline Normal (\%) & 46.2 & 42.9 & 50.0 & NA & $\mathrm{NA}$ & 85.4 & $\mathrm{NA}$ & NA \\
\hline T score $<-1(\%)$ & 43.0 & 42.8 & 43.3 & NA & NA & 14.6 & NA & NA \\
\hline T score $<-2.5(\%)$ & 10.8 & 14.3 & 6.7 & NA & NA & 0 & NA & $\mathrm{NA}$ \\
\hline $\mathrm{L} 2-\mathrm{L} 4\left(\mathrm{~g} / \mathrm{cm}^{2}\right)$ & $1.035(0.165)$ & $1.013(0.128)$ & $1.029(0.131)$ & 1.185 & 0.240 & $1.159(0.123)$ & 6.708 & $<0.001$ \\
\hline L2-L4 (Z score) & $-0.618(1.057)$ & $-0.729(1.122)$ & $-0.465(0.974)$ & 1.005 & 0.319 & $0.082(1.080)$ & 4.335 & $<0.001$ \\
\hline L2-L4 (T score) & $-1.108(1.110)$ & $-1.236(1.136)$ & $-0.950(1.076)$ & 1.050 & 0.298 & $0.275(1.045)$ & 9.188 & $<0.001$ \\
\hline Normal (\%) & 46.3 & 43.2 & 50.0 & NA & NA & 87.6 & NA & NA \\
\hline T score $<-1(\%)$ & 44.7 & 46.0 & 43.3 & NA & NA & 12.4 & NA & $\mathrm{NA}$ \\
\hline T score $<-2.5(\%)$ & 9.0 & 10.8 & 6.7 & NA & NA & 0 & NA & $\mathrm{NA}$ \\
\hline Femoral neck $\left(\mathrm{g} / \mathrm{cm}^{2}\right)$ & $0.860(0.173)$ & $0.828(0.203)$ & $0.880(0.152)$ & 0.902 & 0.370 & $0.941(0.122)$ & 4.531 & $<0.001$ \\
\hline Femoral neck ( $Z$ score) & $-0.245(1.347)$ & $-0.322(1.468)$ & $-0.112(1.176)$ & 0.640 & 0.524 & $0.026(0.955)$ & 1.751 & 0.081 \\
\hline Femoral neck (T score) & $-0.504(1.432)$ & $-0.698(1.585)$ & $-0.314(1.258)$ & 0.995 & 0.323 & $0.101(1.080)$ & 3.786 & $<0.001$ \\
\hline Normal (\%) & 69.6 & 68.4 & 71.0 & NA & NA & 87.6 & NA & NA \\
\hline T score $<-1(\%)$ & 19.8 & 13.2 & 29.0 & NA & NA & 12.4 & NA & NA \\
\hline T score $<-2.5(\%)$ & 10.6 & 18.4 & 0 & NA & NA & 0 & NA & NA \\
\hline
\end{tabular}

Data are shown as mean (s.d.). p-value $<0.05$ defined as significant. AN: anorexia nervosa, RAN: anorexia nervosa, restricting type, BPAN: anorexia nervosa, binge purging type, BMD: bone mineral density, NA: not applicable

Table 6. Regression models of lumbar spine and femur neck BDM in women with AN

\begin{tabular}{|c|c|c|c|c|c|c|}
\hline \multirow{3}{*}{$\begin{array}{l}\text { Independent } \\
\text { variables }\end{array}$} & \multicolumn{2}{|c|}{ L1-L4 T score } & \multicolumn{2}{|c|}{ L2-L4 T score } & \multicolumn{2}{|c|}{ Femur neck T score } \\
\hline & \multicolumn{2}{|c|}{$\begin{array}{c}\text { Model: } \mathrm{R}^{2}=0.205 \\
\mathrm{~F}=6.574, \mathrm{p} \text {-value }=0.003\end{array}$} & \multicolumn{2}{|c|}{$\begin{array}{c}\text { Model: } \mathrm{R}^{2}=0.135 \\
\mathrm{~F}=8.303, \mathrm{p} \text {-value }=0.006\end{array}$} & \multicolumn{2}{|c|}{$\begin{array}{c}\text { Model: } \mathrm{R}^{2}=0.319 \\
\mathrm{~F}=12.191, \mathrm{p} \text {-value }<0.001\end{array}$} \\
\hline & $\beta$ & p-value & $\beta$ & $\mathrm{p}$-value & B & $\mathrm{p}$-value \\
\hline$\overline{\text { Age }}$ & $-0.274^{*}$ & 0.034 & -0.218 & 0.091 & $-0.454^{*}$ & $<0.001$ \\
\hline Lowest ever BMI & $0.335^{*}$ & 0.010 & $0.368^{*}$ & 0.006 & $0.284^{*}$ & 0.017 \\
\hline Current BMI & -0.171 & 0.286 & -0.932 & 0.356 & -0.061 & 0.685 \\
\hline Duration of illness & 0.058 & 0.735 & -0.114 & 0.379 & 0.142 & 0.369 \\
\hline Estrogen level & 0.153 & 0.255 & 0.130 & 0.342 & 0.184 & 0.131 \\
\hline
\end{tabular}

p-value $<0.05$ defined as significant. *factors are included in the final regression model for each dependent variables of $t$ scores for bone sites. $\mathrm{AN}$ : anorexia nervosa, BMD: bone mineral density, BMI: body mass index

The frequency of hypokalemia tends to be relatively low, but generally lies in the range of the previously reported rates, from $4.6 \%$ to $20 \%{ }^{3,12}$ Hyponatremia was also less common in our population than that reported in Western society. ${ }^{3}$ This may be due to the potassium rich Korean staple foods, such as Kim-Chi made with cabbage, salt and red pepper, which some Korean patients with eating disorders choose for binge eating. The serum mean potassium and sodium levels in the women with AN were not different from those in the healthy participants. The hypokalemic women with AN were negati- vely correlated with the duration of illness and age in our correlation analyses.

Abnormalities of liver enzymes are well recognized in AN. In our population, an elevation of serum alanine aminotransferase was observed in $12 \%$ of the patients, which is mildly elevated compared with healthy women. Our findings are similar to the elevated alanine aminotransferase levels in the range of $6.5 \%$ to $12 \%$ observed in a previous study of adults with AN. ${ }^{13}$ Malnutrition, ${ }^{13}$ refeeding ${ }^{14}$ and substance abuse, including alcohol, ${ }^{13}$ may be some of the causes of the elevation of 
transaminases in women with AN. The relatively high serum alanine aminotransferase level in the women with restricting type of AN suggest that there is a more sustained malnutritional contribution to liver damage in this group than in the women with the binge purging type of AN. The possible mechanisms for increased live enzyme include live hypoperfusion and ischemia, hepatocyte autophage and depletion of glutathione. ${ }^{15}$

The Korean women with AN have higher concentrations of total cholesterol than the healthy women in our population. The frequency of hypercholesterolemia in the Korean women with AN was $14.5 \%$ when hypercholesterolemia was defined as a total cholesterol level of more than $240 \mathrm{mg} / \mathrm{dL}$. Women with AN generally have a high concentration of total cholesterol compared with healthy women. Our mean level of $188.08 \pm 47.09 \mathrm{mg} / \mathrm{dL}$ in the women with $\mathrm{AN}$ is in a similar range to those previously reported. ${ }^{16,17}$ Although the aetiology of hypercholesterolemia in patients with $\mathrm{AN}$ is not fully understood yet, the relatively low bilirubin levels in our patients with AN support the hypothesis that decreased bile acid synthesis and, therefore, decreased cholesterol catabolism, may contribute to high LDL-cholesterol and total cholesterol levels. ${ }^{18}$

The levels of triiodothyronine and thyroid stimulating hormone in the women with AN were lower than those in the healthy participants. The majority of patients with AN present a condition called 'low T3 (triiodothyronine) syndrome' characterized by low triiodothyronine, normal or low thyroxine and normal thyroid stimulating hormone. ${ }^{19}$ These alterations have been considered to be a consequence of starvation, especially carbohydrate deficiency, as well as of the decreased resting energy expenditure in AN. Our data showing a correlation of the triiodothyronine level with the current BMI support the idea that the low triiodothyronine level was mostly due to the low body weight.

The serum urea nitrogen levels in the women with AN were higher than those in the healthy women, which is different from previous findings in Caucasian AN. ${ }^{15}$ It may suggest a higher prevalence of dehydration in our AN participants. This further suggests the possibility of a risk of prerenal azotemia in women with $\mathrm{AN}$, which was more pronounced in the restricting type than in the binge purging type of $\mathrm{AN}$ in our cohort.

We found a significant reduction in the BMD and a high frequency of osteopenia and osteoporosis in the women with $\mathrm{AN}$, as reported in Caucasian population. ${ }^{20}$ Bone loss in the lumbar spine and proximal femur can be detected within a year of illness and progresses to produce fractures, kyphoscoliosis and chronic pain. ${ }^{21}$ Interestingly, the frequencies of osteopenia and osteoporosis in the Korean patients with AN, viz. in the ranges of $50-90 \%$ and $20-50 \%$, respectively, are rel- atively lower than the prevalence reported in Caucasian population for AN patients with a similar range of BMI to our subjects. ${ }^{3,22-24}$ This is in accordance with previous findings that the BMI of Asians is on average lower than that of Caucasians $^{25}$ and that East Asian women with AN have significantly greater skinfold sums than their North European Caucasian counterparts after adjusting for $\mathrm{BMI},{ }^{8}$ which would justify the use of a lower BMI in Asian women with AN. ${ }^{25}$ Further studies are needed to test the validity of the current diagnostic criteria for weight loss in AN for Asian women using a large population, including people from different Asian countries.

In our study, the lowest-ever BMI was an important determinant of lumbar spine and femoral neck BMD in the women with AN. Age also remained as a significant determinant of BMD at the femoral neck, but not at the lumbar L2-L4 spine, which is in accordance with a previous report that revealed that weight in the acute stage was the main determinant of bone modification at the lumbar spine, and both weight in the acute stage and weight gain were significant determinants of femoral neck bone BMD. ${ }^{23,26}$ There have been contradictory results regarding the association of BMD with different subtypes of AN. ${ }^{23,27,28}$ Our Korean data are in accordance with those of Olmos et al. ${ }^{23}$ that there is no difference in BMD between patients with the restrictive type and the binge-purging type of $\mathrm{AN}$, and that the bone density deficits depend on the BMI in patients with AN.

No differences were found in the medical findings between the subtypes of AN, except for higher levels of alanine aminotransferase, and lower levels of serum creatinine levels in the patients with the restrictive types of AN, whereas higher levels of serum amylase in the patients with the binge purging types of AN. These results contradict those studies which reported that the binge purging types of $\mathrm{AN}$ are often associated with severe medical complications. ${ }^{29,30}$ Our data suggest that medical complications in AN are more closely associated with under-nutritional status, and that this sub-classification does not differentiate the severity of the medical complications.

There are some limitations of this study we need to consider. Firstly, we recruited participants from a single centre in Korea. The centre is the only specialized tertiary referral centre in Korea. So, the subjects in our study may be more representative of hospital population in Korea. Secondly, the data was gathered retrospectively, so we could not strictly control the psychiatric medications. Some medical complications, such as leukocytopenia, are known to be correlated with certain psychotropics. We, however, do not think this led to any biased results, because the assessment was usually carried out as a baseline medical evaluation before starting treatment. Thirdly, our data were primarily descriptive, so comparison of medical complications of Korean women with AN to Caucasian wom- 
en of similar BMI is limited.

In conclusion, our data in Korean patients with $\mathrm{AN}$ show high frequencies of laboratory abnormalities for medical complications. The lowest-ever BMI was an important determinant of BMD in the women with AN. The AN subtypes appear not to be related to the severity of medical complications other than the serum amylase levels. Whereas, in general, similar patterns in the results were observed compared with previous studies involving Caucasian populations, this study showed some different results such as low frequencies of hypokalemia and osteoporosis. These differences may reflect ethnic differences or cultural factors including staple food, which need to be further elucidated. In future study, multicentres in the different Asian countries need to participate to look for the specific ethnic factors including both biological and cultural factors in women with AN.

\section{Acknowledgments}

This work was supported under the framework of the international cooperation program managed by the National Research Foundation of Korea (2011-0030914).

\section{REFERENCES}

1. Keel PK, Dorer DJ, Eddy KT, Franko D, Charatan DL, Herzog DB. Predictors of mortality in eating disorders. Arch Gen Psychiatry 2003;60: 179-183.

2. Papadopoulos FC, Ekbom A, Brandt L, Ekselius L. Excess mortality, causes of death and prognostic factors in anorexia nervosa. Br J Psychiatry 2009;194:10-17.

3. Miller KK, Grinspoon SK, Ciampa J, Hier J, Herzog D, Klibanski A. Medical findings in outpatients with anorexia nervosa. Arch Intern Med 2005; 165:561-566.

4. Lee S. Eating disorders are becoming more common in the East too. BMJ 2000;321:1023.

5. Humphry TA, Ricciardelli LA. The development of eating pathology in Chinese-Australian women: acculturation versus culture clash. Int J Eat Disord 2004;35:579-588.

6. Kim YR, Heo SY, Kang H, Song KJ, Treasure J. Childhood risk factors in Korean women with anorexia nervosa: two sets of case-control studies with retrospective comparisons. Int J Eat Disord 2010;43:589-595.

7. Bachrach LK, Hastie T, Wang MC, Narasimhan B, Marcus R. Bone mineral acquisition in healthy Asian, Hispanic, black, and Caucasian youth: a longitudinal study. J Clin Endocrinol Metab 1999;84:4702-4712.

8. Soh NL, Touyz S, Dobbins TA, Clarke S, Kohn MR, Lee EL, et al. The relationship between skinfold thickness and body mass index in North European Caucasian and East Asian women with anorexia nervosa: implications for diagnosis and management. Eur Eat Disord Rev 2009; 17:31-39.

9. American Psychiatric Association. Diagnostic and Statistical Manual of Mental Disorders, 4th Edition. Washington DC: American Psychiatric Association; 1994.
10. Hutter G, Ganepola S, Hofmann WK. The hematology of anorexia nervosa. Int J Eat Disord 2009;42:293-300.

11. Lambert M, Hubert C, Depresseux G, Berg BV, Thissen JP, deDeuxchaisnes $\mathrm{CN}$, et al. Hematological changes in anorexia nervosa are correlated with total body fat mass depletion. Int J Eat Disord 1997;21: 329-334.

12. Greenfeld D, Mickley D, Quinlan DM, Roloff P. Hypokalemia in outpatients with eating disorders. Am J Psychiatry 1995;152:60-63.

13. Mickley D, Greenfeld D, Quinlan DM, Roloff P, Zwas F. Abnormal liver enzymes in outpatients with eating disorders. Int J Eat Disord 1996;20: 325-329.

14. Halmi KA, Falk JR. Common physiological changes in anorexia nervosa. Int J Eat Disord 1981;1:16-27.

15. Winston AP. The clinical biochemistry of anorexia nervosa. Ann Clin Biochem 2012;49:132-143.

16. Rigaud D, Tallonneau I, Verges B. Hypercholesterolaemia in anorexia nervosa: frequency and changes during refeeding. Diabetes Metab 2009; 35:57-63.

17. Mehler PS, Lezotte D, Eckel R. Lipid levels in anorexia nervosa. Int J Eat Disord 1998;24:217-221.

18. Weinbrenner T, Zuger M, Jacoby GE, Herpertz S, Liedtke R, Sudhop T, et al. Lipoprotein metabolism in patients with anorexia nervosa: a casecontrol study investigating the mechanisms leading to hypercholesterolaemia. Br J Nutr 2004;91:959-969.

19. Kiyohara K, Tamai H, Takaichi Y, Nakagawa T, Kumagai LF. Decreased thyroid triidothyronine secretion in patients with anorexia nervosa: influence of weight recovery. Am J Clin Nutr 1989;50:767-772.

20. Treasure J, Fogelman I, Russell GFM. Osteopenia of the lumbar and femoral neck in anorexia nervosa. Scott Med J 1986;31:206-207.

21. Treasure J, Claudino AM, Zucker N. Eating disorders. Lancet 2010; 375:583-593.

22. Grinspoon S, Thomas E, Pitts S, Gross E, Mickley D, Miller K, et al. Prevalence and predictive factors for regional osteopenia in women with anorexia nervosa. Ann Intern Med 2000;133:790-794.

23. Olmos JM, Valero C, del Barrio AG, Amado JA, Hernandez JL, Menendez-Arango J, et al. Time course of bone loss in patients with anorexia nervosa. Int J Eat Disord 2010;43:537-542.

24. Winston AP, Alwazeer AE, Bankart MJG. Screening for osteoporosis in anorexia nervosa: prevalence and predictors of reduced bone mineral density. Int J Eat Disord 2008;41:284-287.

25. Ung EK. Eating disorders in Singapore: a review. Ann Acad Med Singapore 2003;32:19-24.

26. Serpell L, Treasure J. Osteoporosis : a serious health risk in chronic anorexia nervosa. Eur Eat Disord Rev 1997;5:149-157.

27. Zipfel S, Seibel MJ, Lowe B, Beumont PJ, Kasperk C, Herzog W. Osteoporosis in eating disorders: a follow-up study of patients with anorexia and bulimia nervosa. J Clin Endocrinol Metab 2001;86:5227-5233.

28. Milos G, Spindler A, Ruegsegger P, Hasler G, Schnyder U, Laib A, et al. Does weight gain induce cortical and trabecular bone regain in anorexia nervosa? A two-year prospective study. Bone 2007;41:869-874.

29. Garner DM, Garner MV, Rosen LW. Anorexia nervosa "restricters" who purge: implications for subtyping anorexia nervosa. Int J Eat Disord 1993;13:171-185.

30. Oliosi M, Dalle Grave R. A comparison of clinical and psychological features in subgroups of patients with anorexia nervosa. Eur Eat Disord Rev 2003;11:306-314. 